\title{
Helicobacter pylori infection and fasting plasma glucose concentration
}

\author{
H G Peach, N E Barnett
}

\begin{abstract}
Background-Helicobacter pylori infection raises basal and meal stimulated serum gastrin concentrations and lowers iron stores, which may in turn reduce fasting plasma glucose concentrations in the population.

Aim-To determine whether H pylori infection leads to lower fasting plasma glucose concentrations in the population. Methods-One hundred and seventy three women and 165 men, randomly selected from the electoral rolls of an Australian city, participated in a cardiovascular risk factor survey. Plasma glucose concentrations and $H$ pylori IgG antibody titres were measured. Non-fasting subjects and pregnant women were excluded, as were known diabetics, whose plasma glucose concentrations would be affected by diet and/or medications. Fasting plasma glucose concentrations were logarithmically transformed and the relation with $H$ pylori infection, adjusting for age and other confounding factors, was determined for men and women separately by analyses of variance.
\end{abstract}

27 October 2000

Table 1 Subjects'demographic, lifestyle, and clinical data

\begin{tabular}{|c|c|c|}
\hline & Women & Men \\
\hline Age (median (range)) & $47(19-87)$ & $45(19-83)$ \\
\hline \multicolumn{3}{|l|}{ Vigorous exercise } \\
\hline Participation & $39(25)$ & $23(16)$ \\
\hline Non-participation & $116(75)$ & $122(84)$ \\
\hline \multicolumn{3}{|l|}{ Contraceptive pill } \\
\hline Used & $20(13)$ & \\
\hline Not used & $133(87)$ & \\
\hline Missing & 2 & \\
\hline \multicolumn{3}{|l|}{ Hormone replacement } \\
\hline Yes & $19(12)$ & \\
\hline & $136(88)$ & \\
\hline \multicolumn{3}{|c|}{ Medication affecting plasma glucose } \\
\hline Used & $16(10)$ & $6(4)$ \\
\hline Not used & $139(90)$ & $139(96)$ \\
\hline \multicolumn{3}{|c|}{ Family history of diabetes } \\
\hline Yes & $17(11)$ & $8(6)$ \\
\hline No & $138(89)$ & $137(94)$ \\
\hline \multicolumn{3}{|l|}{ Waist to hips ratio } \\
\hline Normal & $71(46)$ & $116(80)$ \\
\hline Abnormal & $84(54)$ & $29(20)$ \\
\hline \multicolumn{3}{|l|}{ Body mass index } \\
\hline Underweight & $19(12)$ & $7(5)$ \\
\hline Normal & $76(49)$ & $49(34)$ \\
\hline Overweight & $34(22)$ & $67(46)$ \\
\hline & $26(17)$ & $22(15)$ \\
\hline \multicolumn{3}{|l|}{ Currently drinking } \\
\hline Yes & $109(70)$ & $121(83)$ \\
\hline \multirow{2}{*}{\multicolumn{3}{|c|}{ Currently smoking }} \\
\hline & & \\
\hline Yes & $29(19)$ & $39(27)$ \\
\hline No & $126(81)$ & $106(73)$ \\
\hline \multicolumn{3}{|l|}{ Helicobacter pylori status } \\
\hline Positive & $41(28)$ & $47(34)$ \\
\hline Negative & $107(72)$ & $93(66)$ \\
\hline Missing & 7 & 5 \\
\hline \multicolumn{3}{|c|}{ Fasting plasma glucose $(\mathrm{mmol} / \mathrm{l})$ (mean, median } \\
\hline Number & 155 & 145 \\
\hline
\end{tabular}

Values are number (percentage) of subjects except where indicated otherwise. Excludes pregnant women, persons known to have diabetes, and subjects who had not fasted.
Results-Helicobacter pylori infection was significantly associated with fasting plasma glucose concentration among women. Infected women had a lower mean fasting plasma glucose concentration (5.2 $\mathrm{mmol} / \mathrm{litre}$; range, 3.9-8.2) than did non-infected women $\quad(5.4 \mathrm{mmol} / \mathrm{litre}$ range, 3.9-11.1).

Conclusions-Helicobacter pylori infection may lead to lower fasting plasma glucose concentrations among women and should be considered when interpreting concentrations bordering on diabetes.

(F Clin Pathol 2001;54:466-469)

Keywords: Helicobacter pylori; gastrin; glucose; diabetes

Helicobacter pylori infection in humans is recognised as a chronic infection that usually persists indefinitely. ${ }^{1}$ As well as being involved in the development of several diseases, such as peptic ulcer and gastric cancer, $H$ pylori may disturb normal biochemistry. Some of the changes could affect fasting plasma glucose concentrations in the population.

Infected healthy individuals have higher basal and meal stimulated serum gastrin concentrations throughout a 24 hour period than do non-infected people. ${ }^{2}$ Gastrin can inhibit glucose absorption in the small intestine, ${ }^{3}$ and amplifies glucose stimulated insulin release. ${ }^{4}$ A link between $H$ pylori infection, serum gastrin, insulin concentrations, and serum glucose concentrations has been demonstrated in a small group of dyspeptic patients. ${ }^{5}$ Because of the effect of gastrin on insulin release and glucose absorption, infected healthy individuals may have lower postprandial and fasting plasma glucose concentrations than non-infected people.

Two population based studies have shown that $H$ pylori infection can also reduce iron stores in healthy people. ${ }^{6} 7$ Iron stores are positively correlated with blood glucose concentrations. $^{8}$

If $H$ pylori infection leads to lower fasting plasma glucose concentrations in the population, this effect would need to be considered when interpreting concentrations bordering on diabetes. Therefore, we studied the relation between $H$ pylori infection and fasting plasma glucose concentration among adults in the general population.

\section{Methods}

SETTING

Ballarat has a population of $78000,92 \%$ of whom were born in Australia. The prevalence of $H$ pylori infection in the general population is $30.6 \%{ }^{9}$ 
SUBJECTS

The sample was drawn from 173 women and 165 men $>20$ years old who had participated in a cardiovascular risk factor survey. ${ }^{10}$ Two hundred and fifty nine women and 242 men, randomly selected from the electoral rolls, had been invited to participate in the survey $(67 \%$ and $68 \%$ response, respectively).

\section{QUESTIONNAIRE DATA AND PHYSICAL}

MEASUREMENTS

The survey used the National Heart Foundation's procedures for its surveys of Australian capital cities. ${ }^{10}$ Participants had been asked, through a self administered questionnaire, whether they were taking the contraceptive pill or hormone replacement therapy, what medication they had taken in the preceding fortnight, whether they had been told by a doctor that they had diabetes, whether their parents or siblings had diabetes, whether they had undertaken at least three 20 minute sessions of exercise in the preceding week that made them puff and pant, and whether they drank alcohol or smoked regularly. Height and weight had been measured and was used to derive body mass index (BMI) values. Waist and hip circumference had also been measured and these were used to calculate the waist to hip ratio.

Table 2 Relation between fasting plasma glucose and demographic, lifestyle, and clinical variables

\begin{tabular}{|c|c|c|c|c|}
\hline & \multicolumn{4}{|c|}{ Fasting plasma glucose (mmolll) (mean, median, range) } \\
\hline & Women & & Men & \\
\hline \multicolumn{5}{|l|}{ Age } \\
\hline$<55$ & $5.2,5.2,3.9-8.2$ & & $5.3,5.3,4.1-6.9$ & \\
\hline$\geqslant 55$ & $5.7,5.5,4.3-11.1$ & $p=0.001$ & $5.7,5.6,4.6-7.2$ & $p=0.002$ \\
\hline \multicolumn{5}{|l|}{ Vigorous exercise } \\
\hline Participation & $5.2,5.1,3.9-7.9$ & & $5.3,5.4,4.1-6.4$ & \\
\hline Non-participation & $5.4,5.3,4.3-11.1$ & & $5.5,5.4,4.3-7.2$ & \\
\hline \multicolumn{5}{|l|}{ Contraceptive pill } \\
\hline Used & $4.9,4.9,3.9-5.8$ & & & \\
\hline Not used & $5.4,5.3,3.9-11.1$ & $\mathrm{p}=0.002$ & & \\
\hline Missing & 2 & & & \\
\hline \multicolumn{5}{|l|}{ Hormone replacement } \\
\hline Yes & $5.5,5.2,4.1-8.2$ & & & \\
\hline No & $5.3,5.2,3.9-11.1$ & & & \\
\hline \multicolumn{5}{|c|}{ Medication affecting plasma glucose } \\
\hline Raise & $5.7,5.6,4.7-8.2$ & & $5.5,5.6,5.0-5.7$ & \\
\hline Lower & $4.8,4.8,4.7-4.9$ & & $5.1,5.1,5.1-5.1$ & \\
\hline Raise/lower & $5.2,5.2,5.2-5.2$ & & & \\
\hline Not used & $5.3,5.2,3.9-11.1$ & $P=0.026$ & $5.4,5.4,4.1-7.2$ & \\
\hline \multicolumn{5}{|c|}{ Family history of diabetes } \\
\hline Yes & $5.8,5.1,4.7-11.1$ & & $5.3,5.5,4.5-6.0$ & \\
\hline No & $5.3,5.2,3.9-8.2$ & & $5.4,5.4,4.1-7.2$ & \\
\hline \multicolumn{5}{|l|}{ Waist to hips ratio } \\
\hline Normal & $5.3,5.1,3.9-11.1$ & & $5.4,5.4,4.1-7.2$ & \\
\hline Abnormal & $5.4,5.3,4.1-9.6$ & & $5.5,5.4,4.9-7.1$ & \\
\hline \multicolumn{5}{|l|}{ Body mass index } \\
\hline Underweight & $5.1,5.0,3.9-6.3$ & & $4.8,4.6,4.5-5.5$ & \\
\hline Normal & $5.3,5.2,3.9-11.1$ & & $5.4,5.3,4.1-6.9$ & \\
\hline Overweight & $5.4,5.3,4.4-6.5$ & & $5.5,5.4,4.3-7.2$ & \\
\hline Obese & $5.7,5.3,4.7-9.6$ & $\mathrm{p}=0.010$ & $5.7,5.7,4.9-7.1$ & $\mathrm{p}=0.002$ \\
\hline \multicolumn{5}{|l|}{ Currently drinking } \\
\hline Yes & $5.3,5.2,3.9-11.1$ & & $5.4,5.4,4.1-7.2$ & \\
\hline No & $5.4,5.3,4.1-9.6$ & & $5.5,5.4,4.3-7.1$ & \\
\hline \multicolumn{5}{|l|}{ Currently smoking } \\
\hline Yes & $5.1,5.1,3.9-6.3$ & & $5.5,5.4,4.1-6.9$ & \\
\hline No & $5.4,5.3,3.9-11.1$ & & $5.4,5.4,4.3-7.2$ & \\
\hline \multicolumn{5}{|c|}{ Helicobacter pylori status } \\
\hline Positive & $5.2,5.1,3.9-8.2$ & & $5.5,5.4,4.3-7.1$ & \\
\hline Negative & $5.4,5.2,3.9-11.1$ & & $5.4,5.3,4.1-7.2$ & \\
\hline Missing & 7 & & 5 & \\
\hline Number & 155 & & 145 & \\
\hline
\end{tabular}

Excludes pregnant women, persons known to have diabetes, and subjects who had not fasted.
LABORATORY INVESTIGATIONS

Fasting plasma glucose concentrations had been measured by the glucose oxidase procedure with a Beckman glucose analyser. Stored frozen plasma samples were retrieved, thawed, and tested for anti- $H$ pylori IgG antibodies with the Pyloriset EIA-G kit (Pyloriset, Orion Corporation, Orion Diagnostica Espoo, Finland). The kit uses one of the two original Marshall and Warren strains of $H$ pylori for antigen preparation. A cut off antibody titre of 500 was used to classify subjects as positive or negative, as recommended by the manufacturer (sensitivity, $92.5 \%$; specificity, $84.3 \%$ ).

\section{STATISTICAL ANALYSES}

Relations between $H$ pylori status and fasting plasma glucose concentration, and between the latter and demographic and lifestyle variables, were examined first. Fasting plasma glucose concentrations were not normally distributed and any differences were assessed for significance using the Mann-Whitney $U$ test or the Kruskal-Wallis one way anova. The distribution of fasting plasma glucose concentrations was then normalised through logarithmic transformation and analysis of variance was used to compare the mean fasting plasma glucose concentrations of $H$ pylori infected and non-infected subjects, adjusting for age and other confounding factors. Men and women were analysed separately. Subjects who had not fasted were excluded from the analyses. Known diabetic patients and pregnant women were also excluded because of the effect that their diet and/or medication and pregnancy, respectively, might have had on their fasting plasma glucose concentrations and, thus, on the association between $H$ pylori infection and fasting plasma glucose concentration.

Because we did not know whether any association between $H$ pylori infection and plasma glucose concentration might differ between people with and without diabetes, the analysis of variance was repeated after excluding those women with fasting plasma glucose concentrations $\geqslant 7.0 \mathrm{mmol} /$ litre, whom the American Diabetes Association would regard as having undiagnosed diabetes. ${ }^{11}$ The proportion of infected subjects known to have diabetes or having a fasting plasma glucose concentration $\geqslant 7.0 \mathrm{mmol} /$ litre was compared with that of non-infected subjects using Fisher's exact test.

\section{Results}

Of the 173 women who had participated in the cardiovascular survey, 18 were excluded. Eight had not fasted, three were known diabetics, six were pregnant, and one lacked a frozen plasma sample. Of the 165 male participants, 20 were excluded. Ten had not fasted, five were known diabetics, and five lacked a frozen plasma sample.

Table 1 shows the subjects' demographic, lifestyle, and clinical data. Subjects who were excluded because they had not fasted or lacked a frozen plasma sample were similar to those included in the analyses on all the demographic and lifestyle variables listed in table 1, except 
Table 3 Relation between Helicobacter pylori infection and demographic, lifestyle, and clinical variables

\begin{tabular}{|c|c|c|c|c|}
\hline & \multicolumn{2}{|l|}{ Women } & \multicolumn{2}{|l|}{ Men } \\
\hline & $\begin{array}{l}\text { Infected } \\
n(\%)\end{array}$ & Non-infected $n(\%)$ & $\begin{array}{l}\text { Infected } n \\
(\%)\end{array}$ & Non-infected $n(\%)$ \\
\hline \multicolumn{5}{|l|}{ Age: } \\
\hline$<55$ & $24(59)$ & $78(73) \quad \mathrm{p}=0.09$ & $30(64)$ & $68(73)$ \\
\hline$\geqslant 55$ & $17(41)$ & $29(27)$ & $17(36)$ & $25(27)$ \\
\hline \multicolumn{5}{|l|}{ Vigorous exercise } \\
\hline Participation & $11(27)$ & $26(24)$ & $11(23)$ & $11(12) \mathrm{p}=0.08$ \\
\hline Non-participation & $30(73)$ & $81(76)$ & $36(77)$ & $82(88)$ \\
\hline \multicolumn{5}{|l|}{ Contraceptive pill } \\
\hline Using & $3(7)$ & $17(16)$ & & \\
\hline Not using & $38(93)$ & $88(84)$ & & \\
\hline Missing & & 2 & & \\
\hline \multicolumn{5}{|l|}{ Hormone replacement } \\
\hline Yes & $4(10)$ & $13(12)$ & & \\
\hline No & $37(90)$ & $94(88)$ & & \\
\hline \multicolumn{5}{|c|}{ Medication affecting plasma glucose } \\
\hline Raise & $5(12)$ & $7(7)$ & $2(4)$ & $3(3)$ \\
\hline Lower & $1(2)$ & $1(1)$ & $1(2)$ & $0(0)$ \\
\hline Raise/lower & $0(0)$ & $1(1)$ & $0(0)$ & $0(0)$ \\
\hline Not used & $35(85)$ & $98(92)$ & $44(94)$ & $90(97)$ \\
\hline \multicolumn{5}{|c|}{ Family history of diabetes } \\
\hline Yes & $3(7)$ & $14(13)$ & $1(2)$ & $6(7)$ \\
\hline No & $38(93)$ & $93(87)$ & $46(98)$ & $87(94)$ \\
\hline \multicolumn{5}{|l|}{ Waist to hips ratio } \\
\hline Normal & $18(44)$ & $49(46)$ & $35(75)$ & $76(82)$ \\
\hline Abnormal & $23(56)$ & $58(54)$ & $12(26)$ & $17(18)$ \\
\hline \multicolumn{5}{|l|}{ Body mass index } \\
\hline Underweight & $6(15)$ & $12(11)$ & $2(4)$ & $5(5)$ \\
\hline Normal & $18(44)$ & $54(51)$ & $11(23)$ & $36(39)$ \\
\hline Overweight & $8(20)$ & $25(23)$ & $26(55)$ & $38(41)$ \\
\hline Obese & $9(22)$ & $16(15)$ & $8(17)$ & $14(15)$ \\
\hline \multicolumn{5}{|l|}{ Currently drinking } \\
\hline Yes & $23(56)$ & $81(76)$ & $38(81)$ & $79(85)$ \\
\hline No & $18(44)$ & $26(24)$ & 9 (19) & $14(15)$ \\
\hline \multicolumn{5}{|l|}{ Currently smoking } \\
\hline Yes & $6(15)$ & $23(22)$ & $9(19)$ & $28(30)$ \\
\hline No & $35(85)$ & $84(78)$ & $38(81)$ & $65(70)$ \\
\hline Number & 41 & 107 & 47 & 93 \\
\hline
\end{tabular}

Excludes pregnant women, persons known to have diabetes, subjects who had not fasted, and seven women and five men with missing $H$ pylori titres.

that a larger proportion of the excluded males had a normal waist to hip ratio $(100 \%$ v $79 \%$; Fisher's exact text; $p=0.026)$.

Table 2 shows the univariate relation between fasting plasma glucose concentrations and demographic, lifestyle, and clinical variables. Among women, fasting plasma glucose concentrations increased with age, BMI, and the use of medication that could incidentally increase plasma glucose concentration, and were lower among users of the contraceptive pill and among smokers (although not significantly so). Fasting plasma glucose concentrations were lower among $H$ pylori infected than non-infected women, but not significantly so.

Table 3 shows the univariate relation between the demographic, lifestyle, and clinical variables and $H$ pylori infection. A greater proportion of $H$ pylori infected women were over the age of 54, used medication that might incidentally increase their plasma glucose concentration, were overweight or obese, were not using the contraceptive pill, or were nonsmokers. These variables would be expected to mask any hypoglycaemic effect of $H$ pylori infection in a univariate analysis.

After adjusting for the above confounding factors in an analysis of variance, $H$ pylori infection was significantly associated with fasting plasma glucose concentration among women $(p=0.023)$. The precise variables included in the analysis were age (as a continuous variable); use of the contraceptive pill; taking or not taking medication that could incidentally increase and/or decrease plasma glucose concentration; being underweight, normal weight, overweight or obese; and currently a smoker or not. An analysis of variance adjusting for age, BMI, and participation or non-participation in vigorous exercise did not reveal an association between $H$ pylori infection and fasting plasma glucose concentration among men $(\mathrm{p}=0.81)$.

Five women had fasting plasma glucose concentrations $\geqslant 7.0 \mathrm{mmol} /$ litre and may have had undiagnosed diabetes. When the analysis of variance was repeated after excluding these subjects, $H$ pylori infection was still significantly associated with fasting plasma glucose concentration $(\mathrm{p}=0.022)$.

The proportion of subjects known to have diabetes or having a fasting plasma glucose concentration $\geqslant 7.0 \mathrm{mmol} /$ litre was lower among infected than non-infected women (one of $41 v$ six of 109) but not significantly so, although the numbers are small. Corresponding figures for men were three of 49 and three of 95 , respectively.

\section{Discussion}

Ours is the first study to explore the association between $H$ pylori infection and fasting plasma glucose concentration separately among men and women in the general population. Infected women had lower fasting plasma glucose concentrations than non-infected women and the difference became significant after adjusting for age, use of the contraceptive pill, certain medications, and BMI, which would be expected to mask a hypoglycaemic effect of $H$ pylori infection in a univariate analysis. The lack of an association between $H$ pylori infection and fasting plasma glucose concentration among men in the general population, even after adjusting for confounding factors, is in agreement with the results of previous studies among middle aged men in the UK. ${ }^{12}{ }^{13}$

Although one study found no effect of sex on basal serum gastrin concentration, ${ }^{14}$ another found women had higher basal and meal stimulated serum gastrin concentrations than men. ${ }^{15}$ This might explain the effect of $H$ pylori infection on fasting plasma glucose concentrations in women but not in men. Alternatively, in some populations $H$ pylori may be a greater stressor on iron stores in women than in men. ${ }^{7}$

Although the numbers were small, the proportion of subjects with known and undiagnosed diabetes was also lower among the infected women. Studies conducted to date have given conflicting results over the association between diabetes and $H$ pylori infection. One study compared people with diabetes and healthy controls and found a significantly lower prevalence of $H$ pylori infection among older people with type 1 diabetes. ${ }^{16}$ The same study found that younger people with type 1 diabetes had a higher prevalence of $H$ pylori infection. There was no association between $H$ pylori infection and type 2 diabetes, but the number of people with type 2 diabetes was small. Three other studies, in which all or most of the infected and non-infected subjects were patients with coronary heart disease, found no 
association between $H$ pylori infection and diabetes. ${ }^{121718}$ Two studies involved only or mainly men, ${ }^{12}{ }^{17}$ whereas the gender mix of the subjects in the other studies was not disclosed. ${ }^{16} 18$

There is no reason to believe that the association between $H$ pylori infection and plasma glucose concentration in women was the result of bias. Infected and non-infected women were recruited for the cardiovascular survey in the same way, which was unrelated to their plasma glucose concentrations. Moreover, women who were excluded because they had not fasted or lacked a frozen plasma sample were similar to the women included in the analyses on all the variables in table 1 .

It is impossible to tell from a cross sectional study whether the apparent left shift in the distribution of fasting plasma glucose concentrations among women followed or preceded infection with $H$ pylori. However, it is difficult to conceive of a biological mechanism whereby women towards the left of the fasting plasma glucose distribution curve were more likely to become infected. For example, low fasting plasma glucose concentrations do not slow gastric emptying, ${ }^{19}$ and would probably not predispose women to $H$ pylori infection if they did. Diabetic gastroparesis does not predispose people towards Campylobacter pylori infection or histological chronic gastritis. ${ }^{20}$

Our results need to be confirmed in other populations. Because $H$ pylori infection may lead to lower fasting plasma glucose concentrations in women, this should be considered when interpreting concentrations bordering on diabetes.

1 Hunt RH. Helicobacter pylori: from theory to practice. $\mathrm{Am}$ f Med 1996;100:1S-64S

2 Smith JTL, Pounder RE, Nwokolo CU, et al. Inappropriate hypergastrinaemia in asymptomatic healthy subjects in fected with Helicobacter pylori. Gut 1990;31:522-5.
3 Davenport HW. Physiology of the digestive tract. Chicago: Year Book Medical Publishers Inc, 1977.

4 Rehfeld JF, Stadil F. The effect of gastrin on basal and glucose stimulated insulin secretion in man. $f$ Clin Invest 1973;52:1415-26.

5 Acbay O, Celik AF, Gundogdu S. Does Helicobacter pyloriinduced gastritis enhance food-stimulated insulin release? Dig Dis Sci 1996;41:1327-31.

6 Milman N, Rosenstock S, Andersen L, et al. Serum ferritin, haemoglobin and Helicobacter pylori infection: a seroepidemiological survey comprising 2794 Danish adults. Gastroenterology 1998;115:268-74.

7 Peach HG, Bath NE, Farish SJ. Helicobacter pylori infection: an added stressor on iron status of women in the community. Med F Aust 1998;169:188-90.

8 Tuomainem T-P, Nyssonen K, Salonen R, et al. Body iron stores are associated with serum insulin and blood glucose concentration. Diabetes Care 1997;20:426-8.

9 Peach HG, Pearce DC, Farish SJ. Helicobacter pylori infection in an Australian regional city: prevalence and risk factors. Med F A ust 1997;167:310-13.

10 Peach HG, Bath NE. Prevalence and sociodemographic determinants of cardiovascular risk in a rural area. Aust $\mathcal{F}$ Rural Health 1999;7:23-7.

11 Expert Committee on the Diagnosis and Classification of Diabetes Mellitus. Report. Diabetes Care 1997;20:1183-97.

12 Patel P, Mendall MA, Carrington D, et al. Association of Helicobacter pylori and Chlamydia pneumoniae infections with coronary heart disease and cardiovascular risk factors. BMF 1995;311:711-14.

13 Whincup PH, Mendall MA, Perry IJ, et al. Prospective relations between Helicobacter pylori infection, coronary heart disease and stroke in middle aged men. Heart 1996;75: 568-72.

14 Mossi S, Meyer-Wyss B, Renner EL, et al. Influence of Helicobacter pylori, sex and age on serum gastrin and pepsinogen concentrations in subjects without symptoms and patients with duodenal ulcers. Gut 1993;34:752-6.

15 Feldman M, Richardson CT, Walsh JH. Sex-related differences in gastrin release and parietal cell sensitivity to gastrin in healthy human beings. F Clin Invest 1983;71:71520.

16 Martin-de-Argila C, Boixeda D, Luis de DA, et al. Helicobacter pylori infection and diabetes mellitus. Gastroenterology 1998;114:A218.

17 Martin-de-Argila C, Boixeda D, Fuertes A, et al. High prevalence of Helicobacter pylori infection in coronary heart disease demonstrated by the C-urea breath test. Gut 1996;39(suppl 2):A95.

18 Khurshid A, Puetz T, Fenske T, et al. Sero-prevalence of Helicobacter pylori infection in patients with and without angiographic evidence of coronary artery disease. Gastroenterology 1996;110:A154.

19 Nowak TV, Johnson CP, Kalbfleisch JH, et al. Highly variable gastric emptying in patients with insulin dependent diabetes mellitus. Gut 1995;37:23-9.

20 Barnett JL, Behler EM, Appelman HD, et al. Campylobacter pylori is not associated with gastroparesis. Dig Dis Sci 1989;34:1677-80. 